\title{
RECURSOS DE LA REVISTA HTTP
}

\section{RESOURCES OF THE JOURNAL HTTP}

\author{
May Ruiz Troncoso \\ Universidad de Cádiz \\ https://orcid.org/0000-0001-5948-102X \\ mariajose.ruiz@uca.es
}

Cómo citar este artículo: Ruiz, M. (2020).Recursos de la revista http. Hachetetepé. Revista cientifica en Educación y Comunicación, (20), 121-126.doi: http://doi.org/10.25267/Hachetetepe.2020.i20.18

\section{BIBLIOGRÁFICOS}

Almeida, C. D. (2017). Haitianos no Brasil e sua relação com a comunicação, o consumo e o trabalho. São Paulo: Paulus.

Alliaud, A.y Antelo, E. (2008). Los gajes del oficio: ensenãnza, pedagogía y formación. Buenos Aires: Aique Grupo Editor.

Altimir, D. (2010). ¿Cómo escuchar a la infancia? Barcelona: Octaedro.

Angrosino, M. (2008) Etnografia e Observação Participante. São Paulo: Artmed.

Antelo, E. (2005). "Notas sobre la (incalculable) experiencia de educar". En "Educar: ese acto político". Buenos Aires: Ed. Del Estante.

Arroyo, M. G. (2000). Oficio de mestre: imagens e auto-imagens. Petrópolis: Vozes.

Arroyo, M. G. (2009). Imagens quebradas: Trajetórias e tempos de alunos e mestres. Petrópolis: Vozes.

Augusto, S. O. (2015). A experiência de aprender na Educação Infantil. En Flores, M. y Albuquerque, S. (Coord.). Implementação do Proinfância no Rio Grande do Sul: perspectivas políticas e pedagógicas (pp. 111-118). Porto Alegre: EDIPUCRS.

Azevedo, S. (2011). Técnicos Superiores de Educação Social. Necessidade e pertinência de um estatuto profissional. Porto: Fronteira do Caos.

Azevedo, F.y Balça, Â. (2016). Educação literária e formação de leitores. En Azevedo, F.; Balça, Â. (Org.). Leitura e educação literária. Lisboa: Pactor.

Baena, M.; Sáenz, J. y Quintana Cabañas, J. (2002) Pedagogía Social. Madrid: Pub. UNED.

Bagno, M. (2001). Dramática da língua portuguesa: Tradição gramatical, mídia e exclusão social. São Paulo: Loyola.

Buckingham, D. (2005). Educación en medios. Alfabetizacion, aprendizaje y cultura contemporánea. Barcelona: Paidós.

Bandeira, M. (1967). “Grande sertão: veredas”. En Poesia Completa e Prosa. (pp. 590592) Rio de Janeiro: Aguila.

Batista, I. y Paula, E. (2019) Cartas de professoras e alunas: narrativas sobre ausências e presenças da cultura afro-brasileira e africana no currículo escolar. En Paula, E. (org.). Cartas pedagógicas: revistando memórias e experiências em novos tempos. Curitiba: CRV.

Bauli, R. A. (2018). Educador social no brasil: profissionalização e normatização. Tese (Doutorado em Educação). Maringá: Universidad Estadual de Maringá.

Bernfeld, S. (1975). Sísifo o los límites de la educación. Buenos Aires: Siglo XXI. 
Bizzarri, E. (2003). João Guimarães Rosa-Correspondência com seu tradutor italiano. São Paulo: Nova Fronteira.

Bondioli, A. y Mantovani, S. (1998). Manual de Educação Infantil de 0 a 3 anos: uma abordagem reflexiva. Porto Alegre: ArtMed.

Bourdieu, P. y Passeron, J. (2009). A Reprodução: A Reprodução: Elementos para uma Teoria do Sistema de Ensino. Lisboa: Ed. Vega.

Campos, F. y Miranda, R. (2005). A escrita da história. São Paulo: Escala Educacional.

Camors J, (2009). Relaciones entre los conceptos y las políticas: posibilidades, dificultades y desafíos. En Educación Social: Acto político y ejercicio profesional. Montevideo: ADESU - MEC.

Camors, J (2012). El Educador Social en Uruguay: aspectos históricos y fundamentos teóricos que explican la construcción de la figura profesional. Montevideo: Grupo Magro.

Carr, W. (1990). Hacia una ciencia crítica de la educación. Barcelona: Laertes.

Carneiro, R. (2001) Fundamentos da Educação e da Aprendizagem. Vila Nova de Gaia: Fundação Manuel Leão.

Cerisara, A. B. (2002). Professoras de Educação Infantil: entre o feminino e o profissional. São Paulo: Cortez.

Clandinin, D. y Conelly, F. (2011). Pesquisa narrativa: experiências e história na pesquisa qualitativa. Tradução: Grupo de Pesquisa Narrativa e Educação de Professores ILEEL/UFU. Uberlândia: EDUFU.

Contreras, J. (2010). Pedagogías de la experiencia y la experiencia de la pedagogía. En Contreras, J.; Lara, N. P. (Coord.). Investigar la experiencia educativa (pp. 241271). Madrid: Morata.

Cosson, R. (2006). Letramento literário: teoria e prática. São Paulo: Contexto.

Deleuze, G. (1990). ¿Qué es un dispositivo?. En Michel Foucault Filósofo. Barcelona: Gedisa.

Deligny, F. (2015). Lo arácnido y otros textos. Buenos Aires: Cactus.

Delory, M. (2012). Pesquisa biográfica: projeto epistemológico e perspectivas metodológicas. En Abrahão, M.; Passeggi. M. (Org.). Dimensões epistemológicas e metodológicas da pesquisa (auto) biográfica (pp. 71-93) Tomo I. Natal: EDUFRN: Porto Alegre: EDIPUCRS - Salvador: EDUNEB.

Delours, J. (1998). Educação um tesouro a descobrir - Relatório para a UNESCO da Comissão Internacional sobre Educação para o século XXI. Lisboa: Edições ASA.

Dias, S. P. (2018). Educadoras e educadores sociais de Porto Alegre em busca de reconhecimento. Dissertação (Mestrado). Porto Alegre:Pontifícia Universidade Católica do Rio Grande do Sul. Programa de Pós-Graduação em Ciências Sociais. Porto Alegre.

Ferraz, M. (2011). Lembranças de uma amizade. En Grinspum D. y Silva, M. (Orgs). Mariazinha de Rezende e Fusari por ela mesma e pelos amigos (pp. 46-47).São Paulo: Museu LazarSegal.

Fochi, P. S. (2015). Ludicidade, continuidade e significatividade nos campos de experiência. En Finco, D. et al (Coord.). Campos de experiências na escola da infância: contribuições italianas para inventar um currículo de Educação Infantil brasileiro (pp. 221-232). Campinas: SP: Edições Leitura Crítica.

Fontana, A. y Cação, R. (2005). Como nos tornamos professoras? Belo Horizonte: Autêntica. 
Foucault, M. (1987). As palavras e as coisas: uma arqueologia das ciências humanas. São Paulo: Martins Fontes.

Freitas, A. L. (2008). Conscientização (verbete). En D. Streck, E. Redin, y J. Zitkoski (org). Dicionário Paulo Freire (pp. 99-101). Belo Horizonte: Editora Autêntica.

Freire, P. y Guimarães, S. (2003). Sobre educação (Diálogos) V.2. Paz e Terra, São Paulo

Freire, P. (1967). Pedagogia do Oprimido. Rio de Janeiro: Paz e Terra.

Freire, P. (1989). Educadores de rua: uma abordagem crítica: Alternativas de entendimento aos meninos de rua. Bogotá: Gente Nueva.

Freire, P. (1990). La naturaleza política de la educación. Cultura, poder y liberación. Barcelona: Paidós.

Freire, P. (1993). Anotações sobre Unidade na Diversidade. En Freire, P. Política e Educação.(pp. 31-36). São Paulo: Cortez.

Freire, P. (1996). Pedagogia da autonomia: saberes necessários à prática educativa. São Paulo: Paz e Terra.

Freire, P. (1997). Pedagogia da Esperança: Um reencontro com a Pedagogia do Oprimido. Rio de Janeiro: Paz e Terra.

Freire, P. (2000). Pedagogia da Indignação: cartas pedagógicas e outros escritos. São Paulo: Paz e Terra.

Freire, P.; Araujo, A. (2001). Pedagogia dos sonhos possíveis. São Paulo: UNESP.

Freire, P. (2002) Pedagogia do Oprimido. Rio de Janeiro: Ed. Paz e Terra.

Freire, P. (2006). Conscientização: Teoria e prática da libertação: Uma introdução ao pensamento de Paulo Freire. São Paulo: Centauro.

Freire, P. (2011). Pedagogia da Esperança: um reencontro com a pedagogia do oprimido. São Paulo: Paz e Terra.

García Garrido, J. L. (1986). Fundamentos de Educación Comparada. Madrid: Dickinson.

Guimarães Rosa. J. (2003). João. Correspondência com seu tradutor alemão Curt MeyerClason: (1958-1967). Rio de Janeiro: Nova Fronteira: Academia Brasileira de Letras; Belo Horizonte, MG: Ed. da UFMG.

Guimarães Rosa. J. (1976). Grande sertão: veredas. Rio de Janeiro: José Olympio.

Guimarães Rosa. J. (2001). Primeiras estórias. Rio de Janeiro: Nova Fronteira, 122.

Guimarães Rosa. J. (1979). Sagarana. Rio de Janeiro: José Olympio.

Gray, D. E. (2011). Pesquisa no mundo real. Métodos de Pesquisa. Porto Alegre: Penso.

Hoyuelos, A. (2009). La ética en el pensamiento y obra pedagógica de Loris Malaguzzi. Barcelona: Octaedro.

Jung, C. G. (2002). Recuerdos, sueños, pensamientos. Buenos Aires: Planeta.

Kulisz, B. (2004). Professoras em cena: o que faz a diferença. Porto Alegre: Mediação.

Larrosa, J. (1995). Tecnologías del Yo en la educación en Escuela, poder y subjetivación. Madrid: De la Piqueta.

Malaguzzi, L. (2011). La educación infantil en Reggio Emilia. Barcelona: Octaedro.

Meirieu, P. (2001). La opción de educar. Barcelona: Octaedro.

Mialert, Gaston. (1980). As Ciências da Educação. Lisboa: Moraes Editores.

Moraes, A. C; Paiva, D. L. (2018) Cartas pedagógicas: reflexões de docente da educação básica e ensino superior. Fortaleza: EdUECE.

Morales, M. (2017). Más allá de la práctica educativa. En V. Müller (Coord.) Pedagogia social e edacaçao social. Reflexões sobre as práticas educativas no Brasil, Uruguai e Argentina (Vol II). Curitiba: APPRIS.

e-ISSN:2172-7910

Doi: http://doi.org/10.25267/Hachetetepe.2020.i20.18

Universidad de Cádiz 
Müller, V. y Rodrigues, P. (2002). Reflexões de quem navega na Educação Social: uma viagem com crianças e adolescentes. Maringá: Clichetec.

Natali, P. (2009). O Lúdico em Instituições de Educação Não-formal: cenários de múltiplos desafios, impasses e contradições. Dissertação de Mestrado em Educação. Ponta Grossa.

Natali, P. (2016). Formação profissional na educação social: subsidios a partir de experiências de educadores sociais latino americanos. Tese de Doutorado em Educação. Universidade Estadual de Maringá.

Núñez, V. (Coord.) (2018). Encrucijadas de la educación social. Orientaciones, modelos y prácticas. Barcelona: Editorial UOC.

Ongari, B.; Molina, P. (2005). A educadora de creche: construindo suas identidades. São Paulo: Cortez.

Oliveira-Formosinho, J. (2007). Pedagogia(s) da infância: reconstruindo uma práxis de participação. En Oliveira-Formosinho, J. et al (Coord.). Pedagogia(s) da Infância: dialogando com o passado, construindo o futuro (pp. 13-36). Porto Alegre: Artmed.

Ostetto, L. E. (2008). O estágio curricular no processo de tornar-se professor. En Ostetto, L. E. (Coord.). Educação Infantil: saberes e fazeres da formação de professores. (pp. 127-138). Campinas, SP: Papirus.

Paula, E. M. A. T. (org). (2018). Cartas pedagógicas: estratégias didáticas revisitadas para novos tempos. Curitiba: CRV.

Pérez-Serrano, G. (2003). Pedagogía Social-Educación Social. Construcción científica e intervención práctica. Madrid: Narcea.

Ribas Machado, É. (2010). A constituição da Pedagogia Social na realidade educacional brasileira. Dissertação (Mestrado). Florianópolis: Universidade Federal de Santa Catarina.

Ribas Machado, É. (2014). O desenvolvimento da Pedagogia Social sob a perspectiva comparada: o estágio atual no Brasil e Espanha. Tese (Doutorado em Educação). Sao Paulo: Universidad de São Paulo.

Rinaldi, C. (2008). Reggio Emilia: a imagem da criança e o ambiente em que ela vive como princípio fundamental. En Gandini, L; Edwards y C. Bambini: a abordagem italiana à Educação Infantil (pp. 75-80). Porto Alegre: Artmed.

Rinaldi, C. (2012). Diálogos com Reggio Emilia: escutar, investigar e aprender. São Paulo: Paz e Terra.

Rodrigues, F. (1999). Assistência Social e Políticas Sociais em Portugal. Lisboa: ISSScoop.

Rogers, C. (1986). Libertad y creatividad en la educación en la década de los ochenta. Barcelona: Paidós.

Roig-Rechou, B. (2013). Educação literária e Literatura Infanto-juvenil. Porto: Editora Tropelias \& Companhia.

Russo, D. (2007). De como ser professor sem dar aulas na escola da infância. En Faria, A. (Coord.). O coletivo infantil em creches e pré-escolas (pp. 67-93). São Paulo: Cortez.

Sader, E. Gentilli, P. (orgs). (2008). Pós-neoliberalismo: as políticas sociais e o Estado democrático: As políticas sociais e o Estado democrático. Sao Paulo:Paz e Terra.

Sayad, A. (1998). A imigração ou os paradoxos da alteridade. São Paulo: Editora da Universidad de São Paulo.

e-ISSN:2172-7910

Doi: http://doi.org/10.25267/Hachetetepe.2020.i20.18

Universidad de Cádiz 
Silva, I. (2003). Profissionais da Educação Infantil: formação e construção de identidades. São Paulo: Cortez.

Silva, M. (2001). Mariazinha, uma educadora a frente do seu tempo. En Grinspum D. y Silva, M. (Orgs). Mariazinha de Rezende e Fusari por ela mesma e pelos amigos (pp. 43-44). São Paulo: Museu LazarSegal.

Santos, B. y Meneses, M. (2009). Epistemologias do Sul. Edições Almedina: Coimbra.

Souza, C. (2016). Educação Social e Avaliação: indicadores para contextos educativos diversos. Tese de Doutorado. Maringá: Universidade Estadual de Maringá.

Tardif, M.; Lessard, C. (2014). O trabalho docente: elementos para uma teoria da docência como profissão de interações humanas. Petrópolis: Vozes.

Vigotski, L. S. (2009). Imaginação e criação na infância. São Paulo: Ática.

Warschauer, C. (2017). Rodas em rede: oportunidades formativas na escola e fora dela. Rio de Janeiro: Paz e Terra.

\section{HEMEROGRÁFÍA}

Aptses, Associação dos Profissionais Técnicos Superiores de Educação Social. (2018). Revista Praxis Educare. Porto, Portugal.

Azevedo, S. y Correia, F. (2013). A Educação Social em Portugal: evolução da identidade profissional. Revista de Educación Social (RES), 17.

Bauli, R. y Muller, V. (2019). Evolução e perspectivas da Normatização da profissão do educador social no Brasil. Convergencias. Revista de Educación, 2; 153-171.

Bezerra, I. (2017). Aprendendo a ensinar coletivamente: A Aprendizagem Colaborativa na Musicalização Infantil na UFPB. En XI Conferência Regional Latino Americana de Educação Musical Da ISME, Natal.

Brasil. CNE. Resolução CEB no 01, de 07 de abril de 1999. Define as Diretrizes Curriculares Nacionais para a Educação Infantil. Diário Oficial da União, Brasília, DF, 13 abr. Seção 1; p. 18.

Díaz Puppato, D. (2019). Las prácticas de la enseñanza en la Educación Social: encuentros y tensiones desde una perspectiva didáctica. Convergencias. Revista De educación, 2(4); 129-151.

Drumond, V. (2019). Estágio e docência na Educação Infantil: questões teóricas e práticas. Olhar de Professor, 22; 1-13.

Fusari, M. F. R. (1995). TV, Recepção e Comunicação na Formação Inicial de Professores em Cursos de Pedagogia. Perspectiva: Educação e Comunicação, 13(24); 67-91.

Hall, S. (1997). A Centralidade da Cultura: notas sobre as revoluções de nosso tempo. Educação \& Realidade, 22(2).

Joint, L. A. (2008). Sistema educacional e desigualdades sociais no Haiti: o caso das escolas católicas. Revista Pro-Posições, 19(2); 181-191.

Mantovani, S. y Perani, R. (1999). Uma profissão a ser inventada: o educador da primeira infância. Revista Pro-Posições, 10(1); 75-98.

Mesquida, P. (2011). Paulo Freire e Antonio Gramsci: a filosofia da práxis na ação pedagógica e na educação de educadores. Revista Histedbr On-line, 43; 32-41.

Moraes, A. y Castro, F. (2018). Por uma estetização da escrita acadêmica: poemas, cartas e diários envoltos em intenções pedagógicas. Revista Brasileira de Educação, 23.

Netto, C. et al. (2011). Cartas: um instrumento desvelador que faz a diferença no processo educacional. Revista Educação por Escrito - PUCRS, 2(1). 
Ribeiro, M. E. M.; Ramos, M. G. (2012). Grupos Colaborativos como estratégia de aprendizagem em aulas de química. Acta Scientiae, 14(3).

Soares, I. (2018). Educomunicação, paradigma indispensável à renovação curricular no ensino básico no Brasil. Comunicação \& Educação, 23; 7-24.

Sousa, M. y Cabral, C. (2015). A narrativa como opção metodológica de pesquisa e formação de profesores. Revista Horizontes, 33(2); 149-158.

Souza, C. y Natali, P. (2017). Educação Social e avaliação: crianças e adolescentes como sujeitos avaliadores da prática educativa. Ensino \& Pesquisa, 15(2); 223-236.

Troncareli, M. y Faria, A. (2014) A aprendizagem colaborativa para a interdependência positiva no processo ensino aprendizagem em cursos universitários. Educação, Santa Maria, 39(2); 427-444.

\section{WEBGRÁFÍA}

Brasil. Ministério da Educação (2015). Base Nacional Comum Curricular. Brasília: MEC/SEB. Recuperado de: http://basenacionalcomum.mec.gov.br

Capelle, M. C. y otros (2010). Um Exemplo do Uso da História Oral como Técnica Complementar de Pesquisa em Administração. Anais do VI Encontro de estudos organizacionais da ANPAD; 1-13. Recuperado de: http://www.anpad.org.br/admin/pdf/eneo117.pdf

Cecílio, C. (2019). Como usar Guimarães Rosa para despertar a vontade de ler e escrever. Revista Nova Escola. Recuperado de: https://novaescola.org.br/conteudo/18389/como-usar-guimaraes-rosa-paradespertar-nos-alunos-a-vontade-de-ler-e-escrever

Fenske, E. (2018). Aforismos em Grande Sertão: veredas. Recuperado de: http://www.elfikurten.com.br/2011/01/grande-sertao-veredas-aforismos.html

Ferreira, P. (2017). Modelos ideais de educação mobilizaram brasileiros ao longo da história. Agência Brasil. Recuperado de: http://www.encurtador.com.br/ouWZ1

Informe Final de la Comisión de Implementación del IUDE. (2010). Montevideo. Recuperado de: https://educacion.mec.gub.uy/snep/INFORME\%20FINAL\%20COMISION\%20 DE\%20IMPLANTACION\%20DEL\%20IUDE\%20junio\%202010.pdf

Lopes, P. (2011). Literacia(s) e literacia mediática. CIES-IUL. Recuperado de: encurtador.com.br/rtAOT

Oliveira, Z.; Silva, A.; Cardoso, F. y Augusto, S. (2006). Construção da identidade docente: relatos de educadores de educação infantil. Cadernos de. Pesquisa. 36(129); 547-571. Recuperado de: http://www.scielo.br/pdf/cp/v36n129/a0336129.pdf.

Ruggiero, G. (2012). La formación de los profesores de Filosofía o la paradoja del "giro filosófico". Educar em Revista, 46; 99-112. Recuperado de: https://dx.doi.org/10.1590/S0104-406020120004000

Scliar, M. (2003). A arte de escrever cartas. Recuperado de: https://www.cartamaior.com.br/?/Editoria/Midia-e-Redes-Sociais/A-arte-deescrever-cartas/12/4350 